\title{
Magnetic Properties of Ni-Zn Ferrites by Citrate Gel Method
}

\author{
K. Rama Krishna ${ }^{1}$, K. Vijaya Kumar ${ }^{2}$, C. Ravindernathgupta ${ }^{3}$, Dachepalli Ravinder ${ }^{4}$ \\ ${ }^{1}$ Department of Physics, Malla Reddy College of Engineering \& Technology, Secunderabad, India \\ ${ }^{2}$ Department of Physics, Jawaharlal Nehru Technological University Hyderabad College of Engineering, \\ Nachupally, India \\ ${ }^{3}$ Department of Physics, Government Polytechnic, Nizamabad, India \\ ${ }^{4}$ Department of Physics, Osmania University, Hyderabad, India \\ Email: dachepalli2@rediffmail.com
}

Received June 27, 2012; revised July 29, 2012; accepted August 6, 2012

\begin{abstract}
$\mathrm{Ni}-\mathrm{Zn}$ ferrite with a nominal composition of $\mathrm{Ni}_{1-x} \mathrm{Zn}_{x} \mathrm{Fe}_{2} \mathrm{O}_{4}(x=0,0.2,0.6,0.8,0.9)$ are prepared by citrate gel method and characterized by X-ray diffraction. Magnetic properties of all samples are obtained by using VSM (Vibrating Sample Magnetometer) in the range of 10 Koe. The saturation magnetization values of the samples are carried out from the B-H loop. The effect of composition on saturation magnetization and magnetic moment are studied in this paper. The results showed that Saturation magnetization and magnetic moment values increases gradually as $\mathrm{Zn}^{2+}$ composition increases, it reaches maximum value $70.28 \mathrm{emu} / \mathrm{gm}$ for $(x=0.6)$ and decreases further with increasing $\mathrm{Zn}^{2+}$ composition.
\end{abstract}

Keywords: Ni-Zn Ferrites; Citrate Gel Method: Vibrating Sample Magneto Meter; Saturation Magnetization; Magnetic Moment

\section{Introduction}

Nickel-Zinc ferrites are considered as one of the most versatile soft ferrites because of its high resistance and low eddy current losses [1]. Mixed Ni-Zn ferrite has been commercially used in radio frequency circuits, high quality filters, rod antennas and transformer cores [2,3]. Ni$\mathrm{Zn}$ ferrite is mixed spinel in which the tetrahedral (A) sites are occupied by $\mathrm{Zn}^{2+}$ and $\mathrm{Fe}^{3+}$ ions, and the octahedral sites (B) are occupied by $\mathrm{Ni}^{2+}$ and $\mathrm{Fe}^{3+}$ ions in the spinel formula $\mathrm{AB}_{2} \mathrm{O}_{4}$. The magnetic \& dielectric properties depend on this distribution of these ions on tetrahedral and octahedral sites. This distribution is different when the ferrite is synthesized at low temperature [4]. It is also believed that addition of $\mathrm{Zn}^{2+}$ ions alter the saturation magnetization, lattice parameter and Curie temperature. Several researchers synthesized Ni-Zn ferrite by conventional methods like double sintering method, solid state reaction method, and chemical co precipitation method, hydro thermal process etc. In this context, the objective of this work is to synthesize zinc doped nickel ferrite produced by Citrate gel method and to study their magnetic properties.

\section{Experimental}

Five different compositions of $\mathrm{Ni}_{1-x} \mathrm{Zn}_{x} \mathrm{Fe}_{2} \mathrm{O}_{4}$ with $x=$
$0.0,0.2,0.6,0.8$, and 0.9 are prepared by citrate gel method. The citrate process $[5,6]$ is simple, easy and doesn't require any elaborate and expensive experimental setup. The main advantages of this method is

1) Capacity to yield a homogenous mixture of the constituent ions.

2) As no ball milling is required in this process, there is a little scope of contamination of materials.

3) In case of conventional methods, there is a possibility of introducing iron impurities during milling this leads inhomogenity in sample, which affects the magnetic property.

4) This is a simple method which offers a significant saving in time and energy consumption.

The starting materials used in this preparation are nickel nitrate (Merc, India), zinc nitrate (Merc, India), iron (III) citrate (Merc, India) and citric acid (Merc India) having molar ratio of 1:3 were dissolved in deionized water. Citric acid acts as chelating agent and helps in the homogenous distribution of metal ions. The $\mathrm{pH}$ of the solution is adjusted to 7 by using ammonia solution. The solution was uniformly heated at $373 \mathrm{~K}$ with constant stirring to transform it into a gel and the dried gel was obtained by de hydration process. The dried gel was combusted with evolution of gases and resulted in formation loose powder. This powder is subjected to micro 
wave sintering at $1000^{\circ} \mathrm{C}$ for 30 minutes to get the final product. The X-ray diffraction patterns of the ferrite powder was taken on powder X-ray diffractometer (X-rd) using $\mathrm{Cu}-\mathrm{K}_{\alpha}$ radiation. The Magnetic measurements was carried out by using Vibrating Sample Magneto meter (VSM) in the range of 10 Koe.

\section{Results \& Discussions}

The X-ray diffractogram of Ni-Zn ferrite is shown in
Figure 1, which reveals a single phase cubic spinel structure. The lattice parameter of

$$
a=d\left(h^{2}+k^{2}+l^{2}\right)^{1 / 2}
$$

where, $a=$ lattice constant,

$d=$ inter planar distance and,

$(h, k, l)$ are the Miller indices.

The variation of lattice parameter with $\mathrm{Zn}^{2+}$ composition is shown in the Figure 2. From the figure it can be
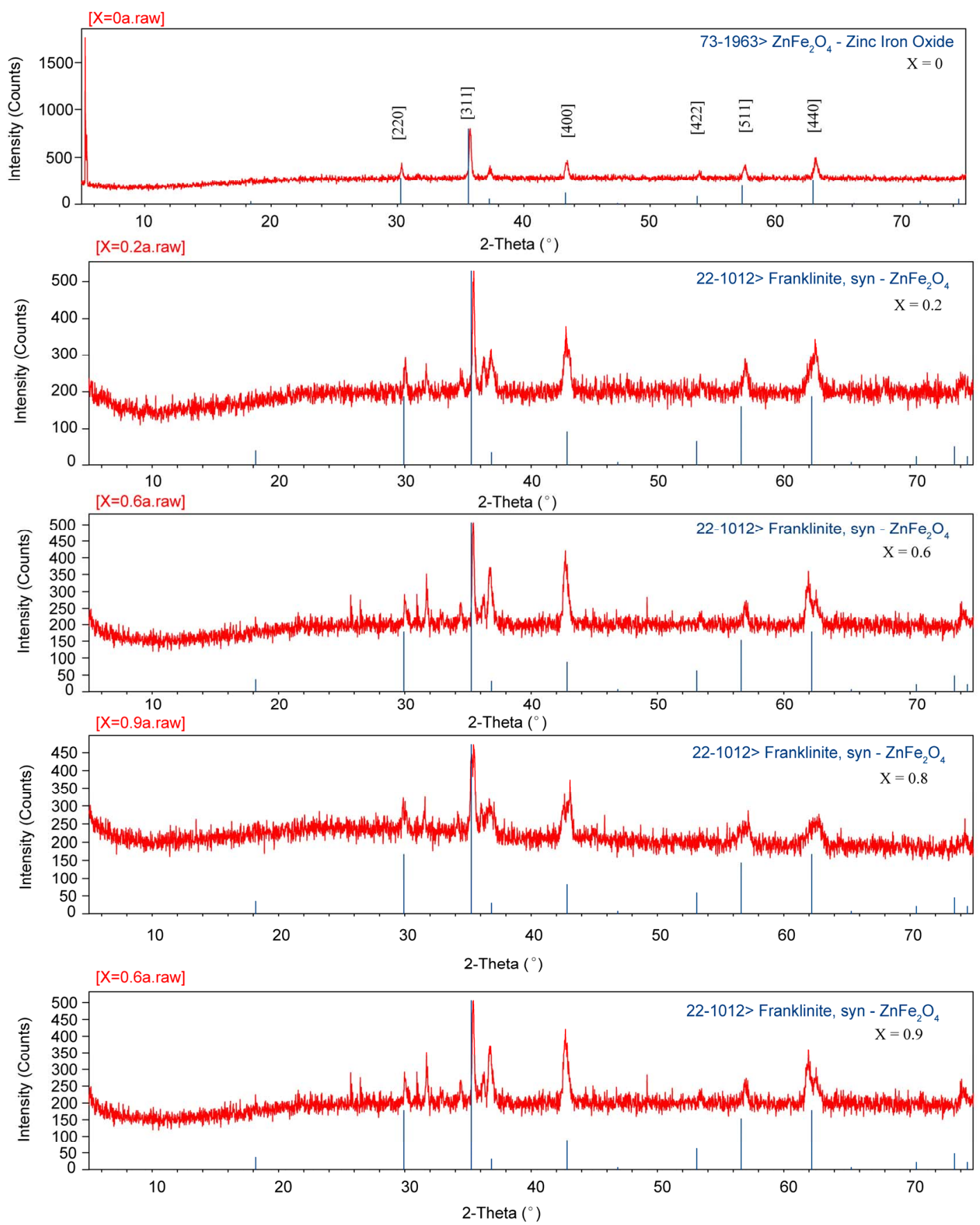

Figure 1. X-ray diffraction studies of mixed Ni-Zn ferrites. 


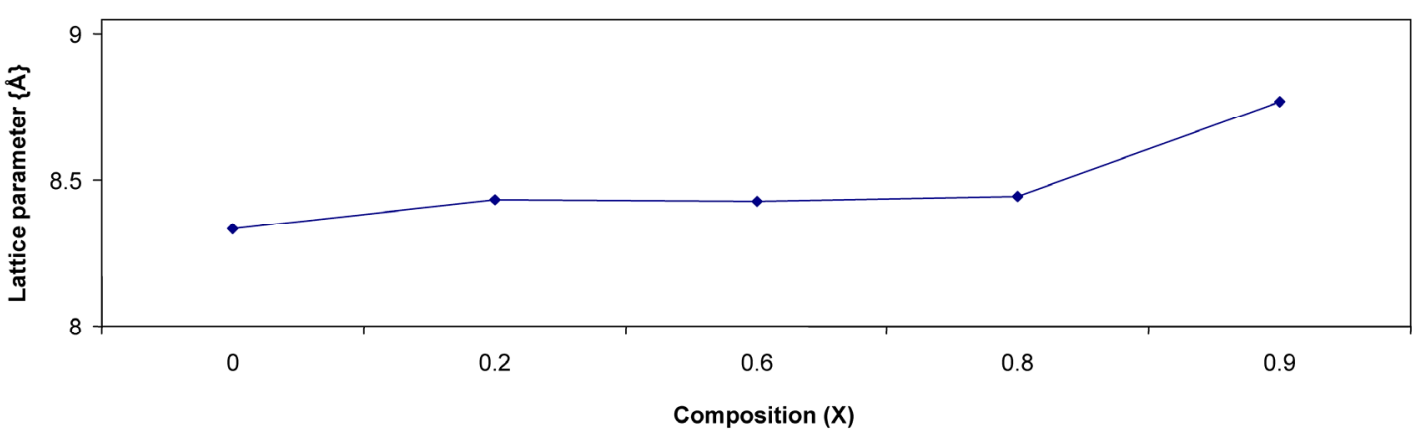

Figure 2. Variation of lattice parameter with composition.

seen that lattice parameter increases with $\mathrm{Zn}^{2+}$ composition. There by it indicating that the Ni-Zn ferrite system obeys Vegard's law [7]. A similar variation also observed by Ravinder in case of $\mathrm{Cu}-\mathrm{Zn}$ ferrites [8]. This variation can be explained on the basis of ionic radius of $\mathrm{Zn}^{2+}$ $(0.82 \AA)$ is greater than $\mathrm{Ni}^{2+}(0.78 \AA)$.

\subsection{Magnetic Properties}

From the VSM data, hystersis loops are plotted as shown in the Figure 3. The variation of saturation magnetization with composition is discussed. It can be seen from the table, that the value of saturation magnetization increases gradually from $\mathrm{X}=0.0$ to 0.6 and reaches to the maximum value of $70.28 \mathrm{emu} / \mathrm{gm}$ for $\mathrm{X}=0.6$ composition and then decreases gradually while $\mathrm{Zn}^{2+}$ composition increases. The behavior of this plot is similar to the [9]. The dependence of saturation magnetization is explained in terms of spin-disorder and spin-canting. In mixed $\mathrm{Ni}-\mathrm{Zn}$ ferrite, the $\mathrm{Zn}^{2+}$ ions concentrate preferentially in the A site and the $\mathrm{Ni}^{2+}$ ions in $B$ site in cubic spinel lattice. When the concentration of $\mathrm{Fe}^{3+}$ ions in the $A$ site is diluted by low concentration of diamagnetic substances such as $\mathrm{Zn}^{2+}$, the net magnetization increases. However magnetization decreases at higher level doping. The reason for this nature is that low $\mathrm{Zn}^{2+}$ concentration reduce the no of spins occupying the $A$ sub lattice, causing the net magnetization increases. As the $\mathrm{Zn}^{2+}$ content increases the exchange interactions are weakened and the $B$ spins are no longer held rigidly parallel to the few remaining $A$ spins. The decrease in $B$ sub lattice moment, interpreted as spin departure from co linearity causes the effect known as canting. Sattar [10] also described this effect in samples of $\mathrm{Cu}-\mathrm{Zn}$ ferrite.

\subsection{Magnetic Moment}

Magnetic Moment is calculated in Bhor Magnetron using the following relation [11] and tabulated in the Table 1.

$$
\begin{aligned}
& m_{B}=\frac{M \times M s}{5585}, \\
& M=\text { Molecular weight of particular composition, }
\end{aligned}
$$

$M s=$ Saturation Magnetization

It can be seen from the table that the ferrite with composition $\mathrm{Ni}_{0.4} \mathrm{Zn}_{0.6} \mathrm{Fe}_{2} \mathrm{O}_{4}$ shows highest value of magnetic moment. It is evident from the Table 1, that the magnetic moment increases with $\mathrm{Zn}^{2+}$ composition from $\mathrm{X}=0.0$ to $X=0.6$ reaches to maximum value 70.28 at $X=0.6$ and then decreases. It can be concluded that as $\mathrm{Zn}^{2+}$ replaces magnetic ions from " $A$ " sites. The magnitude of $A$ site moment decreases but the difference between the $A$ site and $\mathrm{B}$ site moment increases, as a result magnetic moment increases but the decrease in magnetic moment after $X=0.8$ indicates the possibility of canted spin (noncollinear) structure in the present system. The decrease in magnetic moment with increase $\mathrm{Zn}^{2+}$ concentration indicating ferromagnetic behavior which decrease with increasing $\mathrm{Zn}^{2+}$ composition [12].

\section{Conclusion}

A series of $\mathrm{Ni}-\mathrm{Zn}$ ferrite with the composition $\mathrm{X}=0.0$, $0.2,0.6,0.8$, and 0.9 are prepared by using citrate precursor method. The lattice parameter increases as $\mathrm{Zn}^{2+}$ compositions is increases, the ferrite with $\mathrm{X}=0.9$ shows highest value of lattice parameter. The values of saturation magnetization, magnetic moment increases gradually from $X=0.0$ to $X=0.6$ reaches the maximum value at $\mathrm{X}=0.6$ and then decreases as $\mathrm{Zn}^{2+}$ composition is increases.

Table 1. Values of the Saturation magnetization and Bhor magnetron $\left(\mu_{B}\right)$ as a function of composition.

\begin{tabular}{ccc}
\hline Composition & $\begin{array}{c}\text { Saturation Magnetization } \\
(\mathrm{emu} / \mathrm{gm})\end{array}$ & $\begin{array}{c}\mu_{B} \text { (Bhor } \\
\text { magnetron) }\end{array}$ \\
\hline $\mathrm{NiFe}_{2} \mathrm{O}_{4}$ & 40.32 & 1.69 \\
$\mathrm{Ni}_{0.8} \mathrm{Zn}_{0.2} \mathrm{Fe}_{2} \mathrm{O}_{4}$ & 42.79 & 1.80 \\
$\mathrm{Ni}_{0.4} \mathrm{Zn}_{0.6} \mathrm{Fe}_{2} \mathrm{O}_{4}$ & 70.28 & 2.99 \\
$\mathrm{Ni}_{0.2} \mathrm{Zn}_{0.8} \mathrm{Fe}_{2} \mathrm{O}_{4}$ & 58.26 & 2.55 \\
$\mathrm{Ni}_{0.1} \mathrm{Zn}_{0.9} \mathrm{Fe}_{2} \mathrm{O}_{4}$ & 44.40 & 1.91 \\
\hline
\end{tabular}




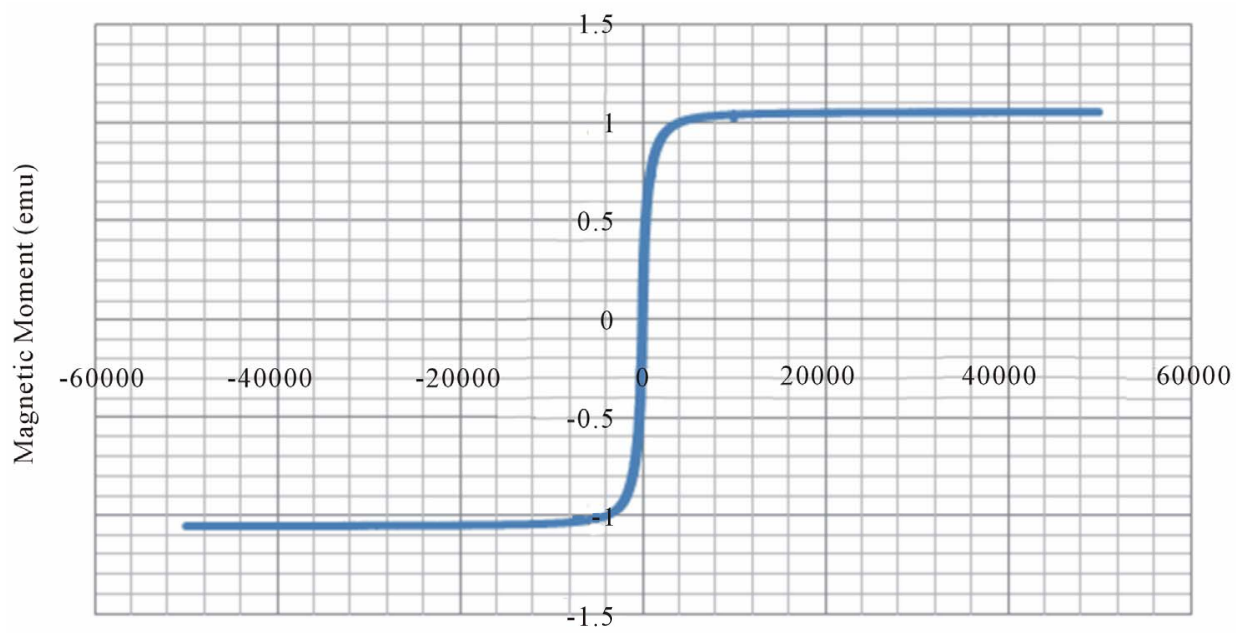

Magnetic Field (Oe)

$$
\mathrm{X}=0.0
$$
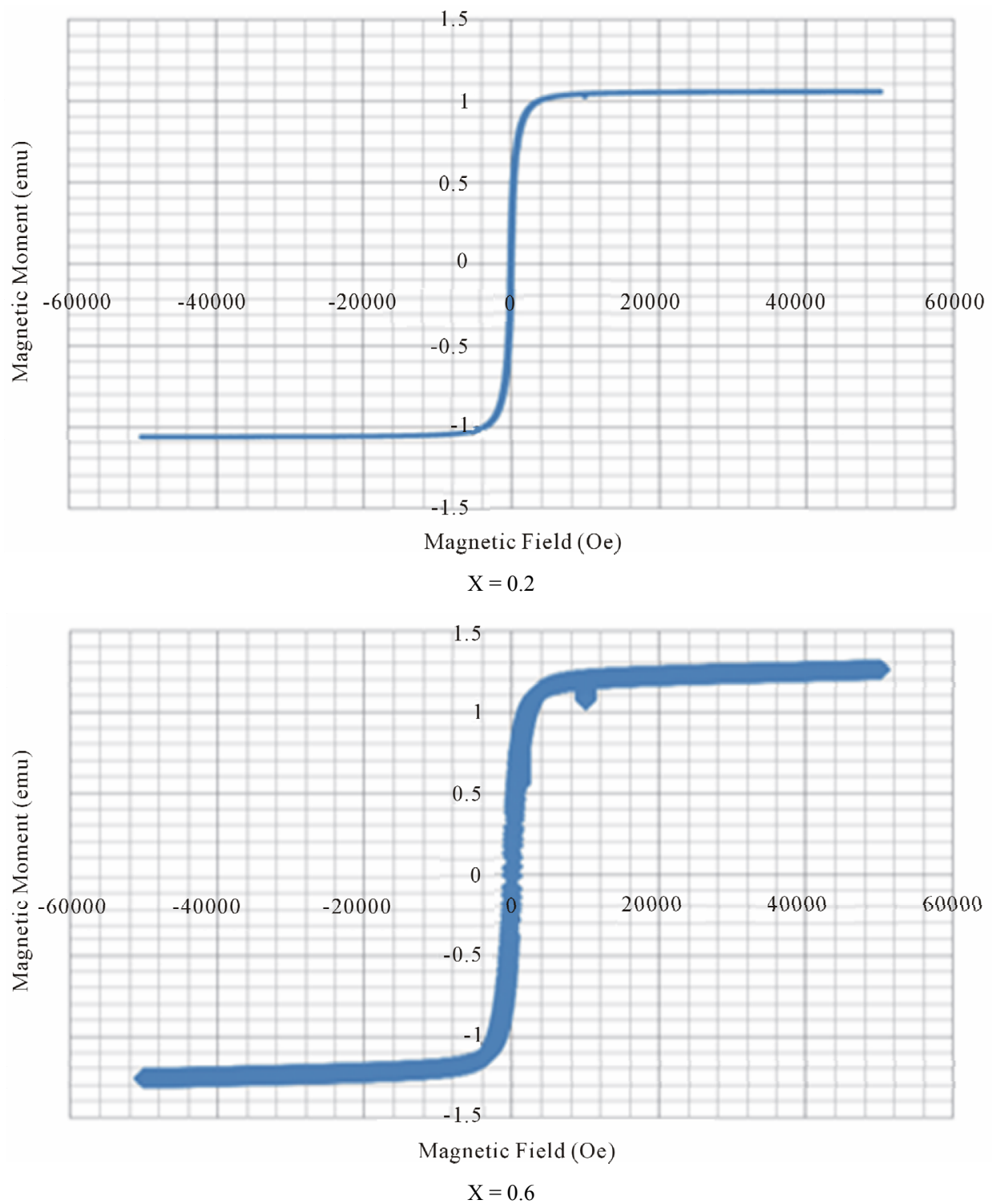

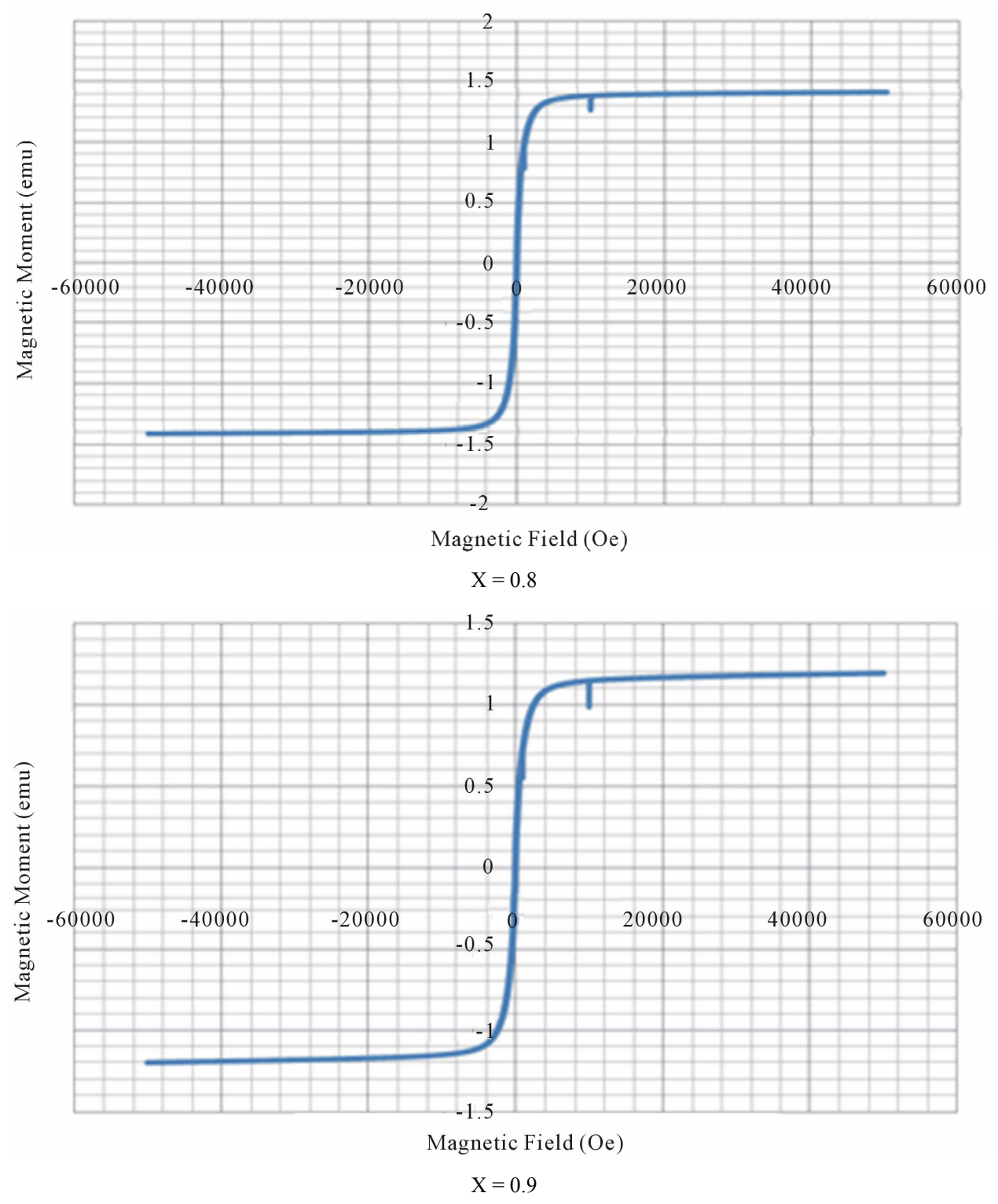

Figure 3. Magnetic hysteresis loops drawn between magnetic field and magnetic moment.

\section{Acknowledgements}

The authors are grateful Prof. P. Kistaiah, Head, Department of Physics, Osmania University, Hyderabad for his encouragement in research work. One of the authors K. Rama Krishna is grateful to V. S. K. Reddy, Principal, Malla Reddy College of Engineering \& Technology, Hyderabad. And the author K. Vijaya Kumar is great ful to Dr. Koorapati Eshwara Prasad, Principal JNTUH College of Engineering, Nachupally, Karim Nagar (Dist).

\section{REFERENCES}

[1] J. P. Chen, C. M. Sorensen, K. J. Kalbunde, H. C. Hadi Panayis, E. Devli and A. Kosikas, "Size-Dependent Magnetic Properties of $\mathrm{MnFe}_{2} \mathrm{O}_{4}$ Fine Particles Synthesized by Coprecipitation," Physical Review, Vol. B54, 1996, pp. 9288-9296.

[2] J. B. Dasilva and N. D. S. Mohallem, "Preparation of Composites of Nickel Ferrites Dispersed in Silica Matrix," Journal of Magnetism and Magnetic Materials, Vol. 226-230, 2001, pp. 1393-1396.

[3] A. M. Abden, "Electric Conduction in Ni-Zn Ferrites," Journal of Magnetism and Magnetic Materials, Vol. 185 1998, p. 199.

[4] C. Y. Tsay, K. S. Liu, T. F. Lin and I. N. Lin, "Microwave Sintering of NiCuZn Ferrites and Multilayer Chip Inductors," Journal of Magnetism Materials, Vol. 209, 2000, pp. 189-192.

[5] A. Verma, T. C. Goel, R. G. Mendiratt and M. I. Alam, "Dielectric Properties of NiZn Ferrites Prepared by the Citrate Precursor Method," Materials Science and Engi- 
neering $B$, Vol. 60, 1999, p. 156.

[6] A. Verma, T. C. Goel and R. G. Mendiratta, "Frequency Variation of Initial Permeability of NiZn Ferrites Prepared by the Citrate Precursor Method," Journal of Magnetism Materials, Vol. 210, 2000, pp. 274-278.

[7] L. Vegard, "Die Konstitution der Mischkristalle und die Raumfüllung der Atome," Zeitschrift für Physik, Vol. 5, No. 1, 1921, pp. 17-26.

[8] D. Ravinder, "Thermoelectric Power Studies of Zinc Substituted Copper Ferrites," Journal of Alloys and Compounds, Vol. 291, 1999, p. 208.

[9] Z. H. Zoha, "Ferrites, Magnetic Materials," (Chinese)
Science Publishing House, Bejing, 1978.

[10] A. A. Sattar, "Magnetic Properties of Cu-Zn Ferrites Doped with Rare Earth Oxides," Physics of the Solid State, Vol. 171, 1999, p. 563.

[11] S. Singhal and K. Chandra, "Cation Distribution and Magnetic Properties in Chromium-Substituted Nickel Ferrites Prepared Using Aerosol Route," Journal of Solid State Chemistry, Vol. 180, 2007, p. 296.

[12] K. B. Modi, H. H. Joshi and R. G. Kulakarani, "Magnetic Ordering in a Zn-Substituted Cu-Fe-Cr-O Ferrite System," Indian Journal of Pure \& Applied Physics, Vol. 34, 1996, p. 93. 